\title{
To clarify the standards of spare parts for technical service of autotractors in zone conditions
}

\author{
Mihail Buraev ${ }^{1, *}$, Alexey Shisteev ${ }^{1}$, Alexandr Zhabin ${ }^{1}$, Anna Anosova ${ }^{1}$, and Petr Ilyin ${ }^{1}$ \\ ${ }^{1}$ Irkutsk State Agricultural University named after A.A. Ezhevsky, 1/1, Molodezhny settlement, \\ 664038, Irkutsk region, Russia
}

\begin{abstract}
Organization of technical service of machines under zone operating conditions provides for the possibility of determining the list of units exposed to climate effects and the estimation of zone correction factors to the consumption rates of spare elements during repair and maintenance [1].
\end{abstract}

\section{Introduction}

An analysis of the publications of authors who conducted such studies in international databases, such as Scopus or Web of Science, showed that there are practically no studies in this area [1]. At the same time, the coefficient of correction of spare parts consumption is calculated in different ways, however, the division of active land use zones by the proposed method will help to recalculate the logistics of operations and make the direction of agriculture even more economically feasible [2].

\section{Materials and discussion}

To determine the coefficients, the calculated discrete function values at the points corresponding to the given climate conditions were corrected in order to exclude the effect of other operational factors. For this, we used the previously obtained values of the partial coefficients of determination. The calculation was carried out according to the formula

$$
k_{i j}=\hat{\mathrm{Z}}_{i j} * d_{i}
$$

where $Z i j-$ is the discrete value of the function at the point corresponding to $\mathrm{j}$ - the climate conditions and to $\mathrm{i}$ - the unit;

$d_{i}$ - is the coefficient of determination, taking into account the cumulative effect of climate conditions.

Thus, a system of coefficients for adjusting the detailed consumption rates of spare units depending on climatic conditions was obtained. However, the use of such a system for planning and practical distribution of spare units turned out to be rather complicated. So, it

\footnotetext{
*Corresponding author: buraev@mail.ru
} 
was proposed to classify the identified list of units in accordance with their climatic reliability. The classification was carried out in the following sequence.

Initially, with the help of logical algorithm, a preliminary selection of the list of units was carried out in order to determine the boundaries of future groups.

Further, in the obtained groups representatives were identified and the remaining units were selected by the degree of proximity to the selected representatives. As a quantitative sign of classified units, we used the coefficients obtained in formula (1), and which are characteristic of a region of very cold climate. Under these conditions the low-temperature influences on the operational characteristics of units, components and assemblies of the car in the highest degree. That allowed us to solve the task easier.

Taking logical signs into account 8 groups of units were obtained. [4]. Let's mark them by $A_{1}, A_{2}, A_{3}, \ldots, A_{8}$. Quantitative characteristics of the obtained groups are given in table 1 . The frequency distribution information of the nomenclature of vehicle parts in accordance with their amenability to climatic effects is given in table 2 and displayed graphically in figure 1.

Not more than $15-20 \%$ of the range of KAMAZ automobile detailes, supplied as spare parts, exposure to low temperatures. And $43.4 \%$ of them represent various rubber products (shock-absorbing parts, movable seals and power transmission seals, protective parts and auxiliary parts of general purpose) and operate at temperatures close to ambient temperature (group A -A ). 32.3\% accounts for engine units and vehicle transmission (A ). $10 \%$ falls on the production of electrical equipment. $8.7 \%$ accounts for car suspension and $5.6 \%$ falls on plain bearings (mainly on car suspension and steering).

It is established, that private distribution of the nomenclature of units in accordance with their amenability to climate effects submites to normal law [6].

In relation to this law, the average values of the correction coefficients of the norms within the obtained groups of units can be determined by the formula

$$
k_{g r}=\bar{k}+1,96 \frac{\sigma}{\sqrt{n_{g r}}}
$$

where $\mathrm{k}$ - the average value of the correction coefficient of norms of the consumption rates of units included in this group for a specified climate region;

$\mathrm{n}_{\mathrm{gr}}-$ the number of units included in this group.

Table 1. Frequency distribution of the nomenclature of car units in accordance with their amenability to low temperatures.

\begin{tabular}{|c|c|c|c|}
\hline \multirow{2}{*}{$\begin{array}{c}\text { The } \\
\text { number } \\
\text { of groups }\end{array}$} & \multicolumn{3}{|c|}{ Group Description } \\
\hline & Representatives & $\Delta \mathbf{k}_{\mathbf{i}}$ & Nomenclature \& number of units \\
\hline $\mathrm{A}_{1}$ & 2.34 & $2.25-2.38$ & $10(3), 13(3), 27(1), 29(3), 50(7)$ \\
\hline $\mathrm{A}_{2}$ & 2.26 & $2.18-2.34$ & $16(3), 17(3), 25(1), 35(21)$ \\
\hline $\mathrm{A}_{3}$ & 2.18 & $2.12-2.24$ & $24(1), 29(2), 31(2), 34(4), 13(2), 35(1)$ \\
\hline $\mathrm{A}_{4}$ & 2.06 & $1.96-2.16$ & $\begin{array}{l}11(9), 13(7), 16(3), 29(1), 34(10), 35(1), \\
38(1), 37(15), 52(2), 56(2), 57(1), 61(7), \\
81(5)\end{array}$ \\
\hline $\mathrm{A}_{5}$ & 1.99 & $1.92-2.03$ & $10(3), 27(2), 29(12), 35(3)$ \\
\hline $\mathrm{A}_{6}$ & 1.94 & $1.88-1.97$ & $27(2), 29(6), 30(1), 34(3), 35(1)$ \\
\hline $\mathrm{A}_{7}$ & 1.86 & $1.77-1.91$ & $37(30)$ \\
\hline $\mathrm{A}_{8}$ & 1.72 & $1.51-1.83$ & $10(17), 16(14), 22(2), 24(16), 25(18)$ \\
\hline
\end{tabular}




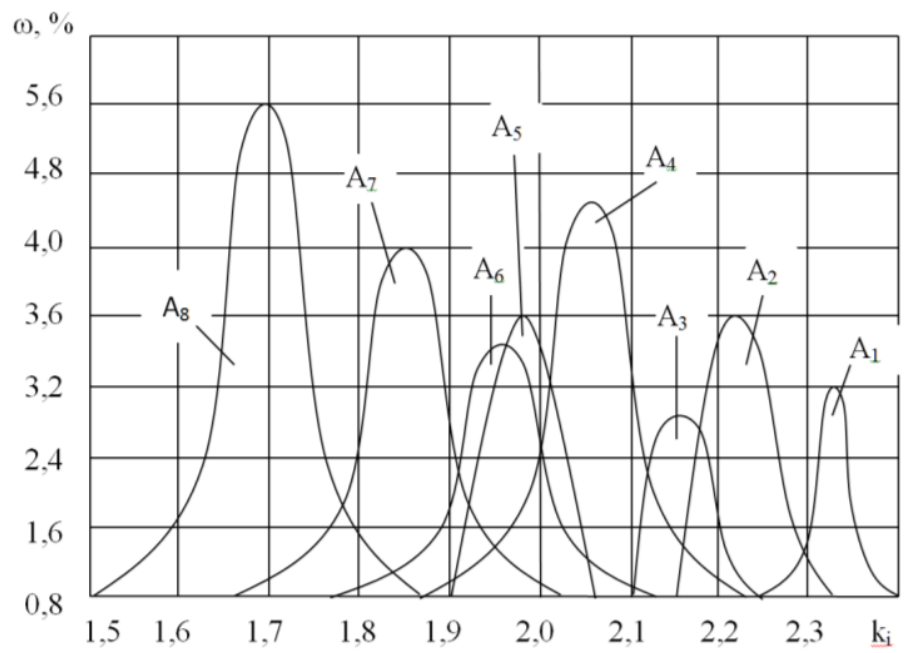

Fig. 1. Distribution of the nomenclature of car units in accordance with their amenability to climate effects.

Table 2. Frequency distribution.

\begin{tabular}{|c|c|c|c|c|c|c|c|c|c|c|c|c|c|c|c|c|c|}
\hline & \multicolumn{10}{|c|}{ Accumulated frequency by part groups } \\
\hline
\end{tabular}




\begin{tabular}{|l|l|l|l|l|l|l|l|l|l|l|l|l|l|l|l|l|}
\hline $2.05-2.06$ & & & & & & & & & 11 & 4.4 & & & & & & \\
\hline $2.07-2.08$ & & & & & & & & & 8 & 3.2 & & & & & & \\
\hline $2.09-2.10$ & & & & & & & & & 3 & 1.2 & & & & & & \\
\hline $2.11-2.12$ & & & & & & & & & 2 & 0.8 & 1 & 0.4 & & & & \\
\hline $2.13-2.14$ & & & & & & & & & & & 4 & 1.6 & & & & \\
\hline $2.15-2.16$ & & & & & & & & & 1 & 0.4 & 2 & 0.8 & & & & \\
\hline $2.17-2.18$ & & & & & & & & & & & 2 & 0.8 & 1 & 0.4 & & \\
\hline $2.19-2.20$ & & & & & & & & & & 1 & 0.4 & 5 & 1.9 & & \\
\hline $2.21-2.22$ & & & & & & & & & & & 2 & 0.8 & 7 & 2.8 & & \\
\hline $2.23-2.24$ & & & & & & & & & & 1 & 0.4 & 6 & 2.4 & & \\
\hline $2.25-2.26$ & & & & & & & & & & & & & 4 & 1.6 & 1 & 0.4 \\
\hline $2.27-2.28$ & & & & & & & & & & & & 2 & 0.8 & 1 & 0.4 \\
\hline $2.29-2.30$ & & & & & & & & & & & & 2 & 0.8 & 2 & 0.8 \\
\hline $2.31-2.32$ & & & & & & & & & & & & & 2 & 0.8 & 5 & 1.9 \\
\hline $2.33-2.34$ & & & & & & & & & & & & 1 & 0.4 & 3 & 1.2 \\
\hline $2.35-2.36$ & & & & & & & & & & & & & & & 2 & 0.8 \\
\hline $2.37-2.38$ & & & & & & & & & & & & & & 1 & 0.4 \\
\hline
\end{tabular}

Note: $\omega_{\text {abs }}-$ absolute frequency; $\omega_{\text {rel }}-$ relative frequency, $\% ; A_{1} \ldots, A_{8}-$ groups of parts obtained as a result of classification.

The use of formula (2) requires the fulfillment of the condition that, with $95 \%$ reliability, the corrected consumption rates across the entire range of units included in this group, correspond to their actual needs. [7, 8].

This approach makes it possible to increase the guarantee that the planned norms for the supply of spare parts according to the nomenclature will correspond to the actual demand for them in areas with cold climate or slightly exceed it. Thus it gives way to be corrected by expert assessment of the obtained values, as well as during the trial implementation of the developed system. Besides this allows to compensate the errors that could have been made during the collection of statistical material and its subsequent processing.

The classification allowed to establish the list of car units included in one or another group. As detailed zone coefficients for consumption rates correction were established at the first stage, so the set of the values for the average group of coefficients in other climate regions was not difficult.

The results of the calculations are shown in table 3. The table shows that in the subgroups $A_{1}-A_{6}$ there is a common feature - "elements which are not protected from the effects of low temperature". This symptom is really common. But we cannot single it out as a unifying feature, because these subgroups subject to amenability of low temperatures in different ways.

To clarify the physical meaning of classification and evaluation of these dependencies obtained in this case, it is advisable to switch from detailed multi-factor models to group one-factor ones. For this, information about representatives of the obtained groups by climate regions and information about average winter temperatures in different zones were entered into block 17.

As a result, mathematical models for changing zone coefficients of adjusting the consumption rates of spare parts were obtained. The validity of the obtained models was checked by using the Fisher criterion, the significance of the coefficients was evaluated by the t-student criterion.

Rubber shock-absorbing products $\left(\mathrm{A}_{1}\right)$

$$
\left.k_{1}=1,516+8,305 * 10^{-2} \bar{t}_{3}+3,33 * 10^{-3} \bar{t}_{3}^{2}\right)
$$

Pneumatic equipment seals $\left(\mathrm{A}_{2}\right)$ 


$$
k_{2}=0,11-1,044 * 10^{-1} \bar{t}_{3}-1,199 * 10^{-3} \bar{t}_{3}^{2}
$$

Sealants for pneumatic equipment $\left(\mathrm{A}_{3}\right)$

$$
k_{3}=0,259-8,018 * 10^{-2} \bar{t}_{3}-6,87 * 10^{-4} \bar{t}_{3}^{2}
$$

Seals for power drives $\left(\mathrm{A}_{4}\right)$

$$
k_{4}=1,46+7,21 * 10^{-2} \bar{t}_{3}+2,785 * 10^{-3} \bar{t}_{3}^{2}
$$

Protective units $\left(\mathrm{A}_{5}\right)$

$$
k_{5}=1,523+7,89 * 10^{-2} \bar{t}_{3}+2,868 * 10^{-3} \bar{t}_{3}^{2}
$$

Plain bearings $\left(\mathrm{A}_{6}\right)$

$$
k_{6}=0,6406-3,597 * 10^{-2} \bar{t}_{3}+1,21 * 10^{-4} \bar{t}_{3}^{2}
$$

Electrical equipment parts $\left(\mathrm{A}_{7}\right)$

$$
k_{7}=0,229-9,005 * 10^{-2} \bar{t}_{3}-1,229 * 10^{-3} \bar{t}_{3}^{2}
$$

Transmission parts $\left(\mathrm{A}_{8}\right)$

$$
k_{8}=0,4056-6,88 * 10^{-2} \bar{t}_{3}-8,75 * 10^{-4} \bar{t}_{3}^{2}
$$

The above dependencies are shown in Figure 2.

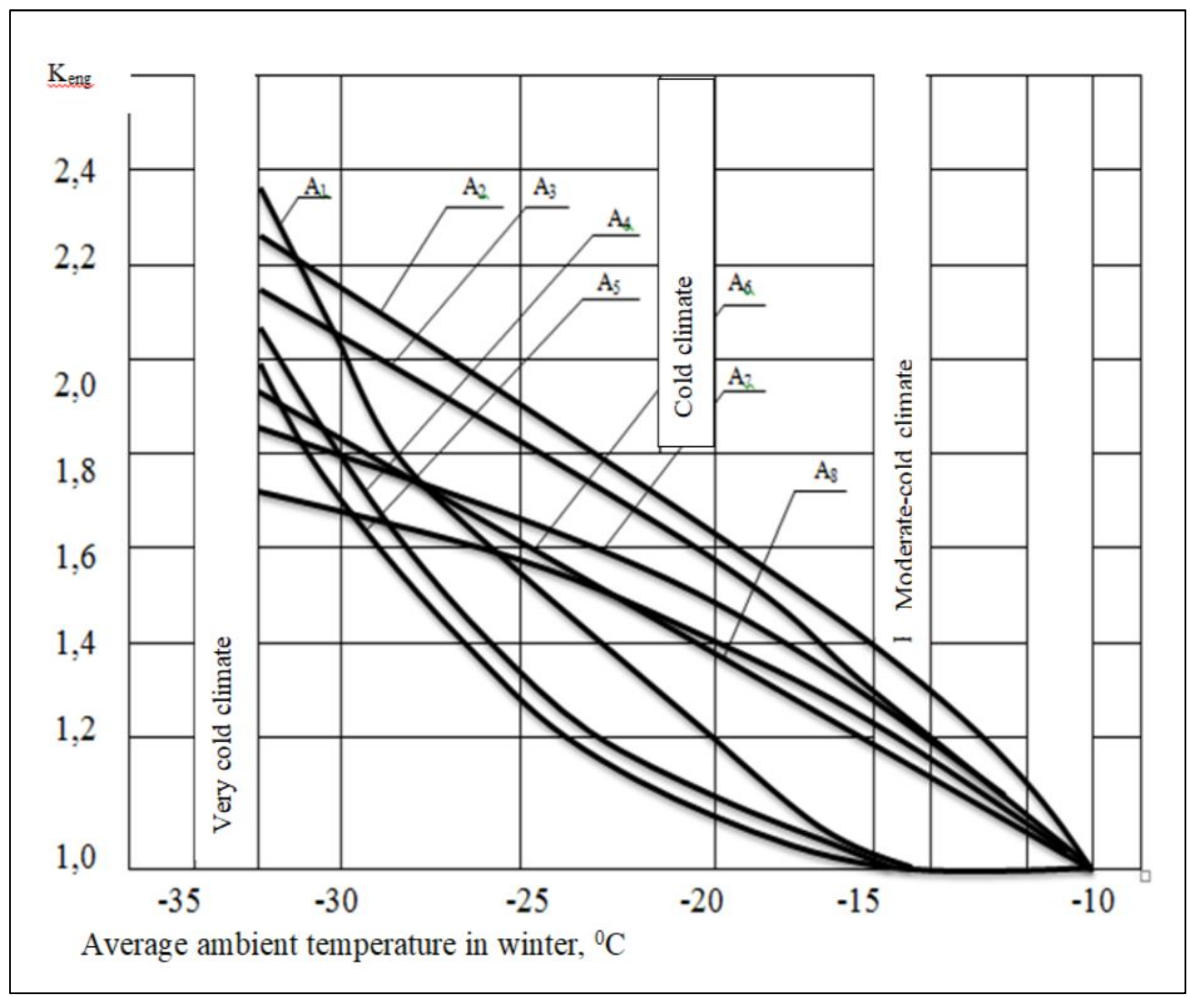

Fig. 2. Changing the zonal coefficients for adjusting the consumption rates of spare parts of KAMAZ vehicles for 1-8 groups of parts. 
The curves on the diagram show the nature of the intensity of the failure of units according to ambient temperature drop. So the failure of 1, 4, 5 groups is characterized by sharp increase in values of degrees of dependence in the zone of very cold climate. Dependence 1 and 4 relate to rubber products which lose their elastic properties, elasticity and become brittle at low temperatures and they can be destroyed under relatively light loads. The physical meaning of dependence 5 is - that suspension units experience increased air resistance as well as pressure of alternating loads. At temperatures below 40 degrees $\mathrm{C}$ these effects significantly change the toughness of steel and lead to its cold brittleness. Moreover, as the car is getting old, destruction can also occur at higher temperatures. The nature of the obtained dependence does not contradict the results of theoretical and practical researches.

Group 2 details relate to pneumatic equipment seals. It was established that at temperatures from -10 to -15 degrees $\mathrm{C}$ (the region of temperate-cold climate) their failures prevail due to the action of condensate (swelling, freezing them to the working edges, etc.) on the operation of the braking system devices. In areas of cold and very cold climates, additional failures are associated with low-temperature destruction of rubber products. [5].

Details of group 3 are also made of rubber. Their reliability is determined by three factors: the growth of the specific load, the deterioration of the physicomechanical properties of the material of the units and physical properties in conjugations during their work. The resource of sliding bearings (group 6) changes under the influence of low temperatures according to a dependence close to straight line. The reason lies in the deterioration of grease conditions of rubbing units as a result of an increase of viscosity of grease.

At first sight, the exposure of electrical products to low temperatures (curve 7) should also be of a proportional nature. However, practically this is not observed. The reason for a rather significant decrease in the reliability of electrical products at a relatively small decrease of ambient temperature should be sought in the fact that in areas of temperatecold, and partially cold climate, garageless storage of cars is mainly provided. Garageless storage of cars requires the more frequent use of devices that provide engine starting and warming up. In winter in the Far North in addition to low temperatures, the following negative factors appear: reduction daylight hours, a significant number of days with fogs, the appearance of gas condensate clouds from passing cars, which reduces visibility almost zero. These factors lead to a more intensive use of lighting devices. Intensive use of lighting devices in combination with functioning electrical appliances of the heating and ventilation systems increases the load on the vehicle's power sources and their electrical protection systems.

Thus, a change in zone coefficients of adjusting the consumption rates of KAMAZ spare parts for 8 groups of units (Figure 4, formulas 3-10) shows that, at low temperatures, units made of rubber materials lose their elastic properties, elasticity, become brittle and under relatively small loads can be destroyed.At the same time at low temperatures cold brittleness of metal units increases and reliability significantly decreases at relatively small temperature drop due to the fact that a lot of cars are used without garage storage [8]. 
Table 3. Zone coefficients of adjusting the consumption rates of spare parts for maintenance and repair of KAMAZ automobiles.

\begin{tabular}{|c|c|c|c|c|c|c|c|c|c|c|}
\hline & \multirow{3}{*}{$\begin{array}{l}\text { Sub } \\
\text { group } \\
\text { index }\end{array}$} & \multicolumn{9}{|c|}{ Group Coefficients } \\
\hline & & \multicolumn{3}{|c|}{$\begin{array}{l}\text { Moderately cold } \\
\text { climate }\end{array}$} & \multicolumn{3}{|c|}{ Cold climate } & \multicolumn{3}{|c|}{ Very cold climate } \\
\hline & & $\overline{\mathbf{k}}_{\mathbf{i}}$ & $\mathbf{k}_{\text {imin }}$ & $\mathbf{k}_{\text {imax }}$ & $\overline{\mathbf{k}}_{\mathbf{i}}$ & $\mathbf{k}_{\text {imin }}$ & $\mathbf{k}_{\text {imax }}$ & $\overline{\mathbf{k}}_{\mathbf{i}}$ & $\mathbf{k}_{\mathbf{i m i n}}$ & $\mathbf{k}_{\text {imax }}$ \\
\hline \multicolumn{11}{|l|}{$\begin{array}{l}\text { 1. Elements that are not } \\
\text { protected from low temperatures }\end{array}$} \\
\hline \multicolumn{11}{|l|}{$\begin{array}{l}1.1 \text { Rubber and polymer } \\
\text { products }\end{array}$} \\
\hline 1.1.1 Shock absorbing details & $\mathrm{A}_{1}$ & 1.03 & 0.97 & 1.06 & 1.15 & 1.07 & 1.18 & 2.34 & 2.25 & 2.38 \\
\hline 1.1.2 Movable seals & $\mathrm{A}_{2}$ & 1.4 & 1.36 & 1.42 & 1.65 & \begin{tabular}{|l|}
1.58 \\
\end{tabular} & 1.69 & 2.26 & 2.18 & 2.34 \\
\hline 1.1.3 Power transmission seals & $\mathrm{A}_{3}$ & 1.32 & 1.28 & 1.35 & 1.56 & 1.51 & 1.60 & 2.18 & 2.12 & 2.24 \\
\hline $\begin{array}{l}\text { 1.1.4 Protective and auxiliary } \\
\text { parts }\end{array}$ & $\mathrm{A}_{4}$ & 1.02 & 1.0 & 1.03 & 1.10 & 1.06 & 1.13 & 2.06 & 1.96 & 2.16 \\
\hline $\begin{array}{l}\text { 1.2 Prone to cold brittle fragility } \\
\text { mechanical components } \\
\text { operating under alternating loads }\end{array}$ & $\mathrm{A}_{5}$ & 1.01 & 0.98 & 1.02 & 1.06 & 1.01 & 1.09 & 1.99 & 1.92 & 2.03 \\
\hline 1.3 Plain bearing & $\mathrm{A}_{6}$ & 1.18 & 1.16 & 1.19 & 1.37 & 1.34 & 1.39 & 1.94 & 1.88 & 1.97 \\
\hline $\begin{array}{l}\text { 2. Products of electrical } \\
\text { equipment of the car. the use of } \\
\text { which increases with a decrease } \\
\text { in ambient temperature }\end{array}$ & $\mathrm{A}_{7}$ & 1.25 & 1.21 & 1.27 & 1.5 & 1.44 & 1.54 & 1.86 & 1.77 & 1.91 \\
\hline $\begin{array}{l}\text { 3. Mechanical parts of the eng. } \\
\text { and transm.. the use of which } \\
\text { increases with a decrease in } \\
\text { ambient temperature }\end{array}$ & $\mathrm{A}_{8}$ & 1.2 & 1.1 & 1.27 & 1.4 & 1.26 & 1.48 & 1.72 & 1.51 & 1.83 \\
\hline
\end{tabular}

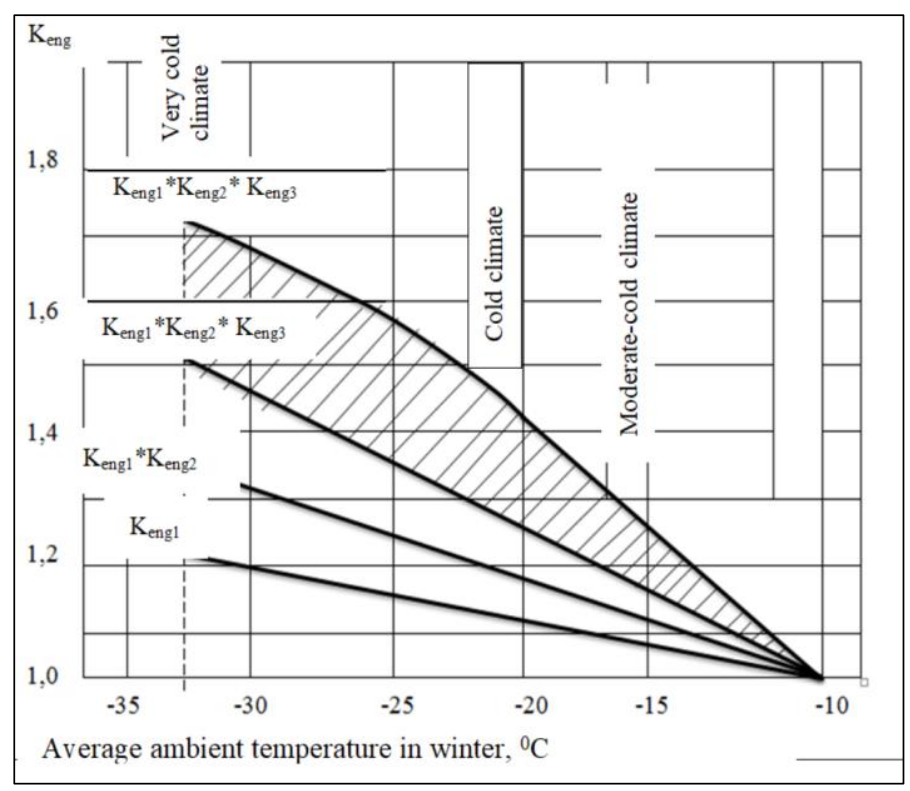

Fig. 3. Shows diagram of changes in the $K_{\text {eng }}$ coefficient and the product of $K_{\text {eng1 }}$ and $K_{\text {eng2 }}$ details. 
Research also allowed us to evaluate the role of the component $\mathrm{k}$. The authors of this work found out that the proportion of wear due to engine start-up heating in cold climate areas reaches $10 \%$, and engine wear pattern depending on the ambient temperature is linear. This statement gives us the right to use the graphical construction to obtain the dependence $\mathrm{k} * \mathrm{k} * \mathrm{k}$ in function of air temperature. Given dependence separates engine start-up wearout from deterioration associated with unsteady thermal conditions of the engine and other reasons. In accordance with the diagram in figure 3 we can make the following conclusion.

If we evaluate the total engine wear due to low temperatures for $100 \%$, then:

- the proportion of unit wear due to influence of cold temperatures at the engine working process will be $21-24 \%$;

- the proportion of unit wear will be $19-23 \%$ if the car overcomes dense air by engine boost;

- wear and tear associated with another factors (the shaded area, Figure 4.3.) makes up $10-15 \%$;

- wear associated with other factors (the shaded area in figures 3 and 4 ) is $38-50 \%$.

Thus, the proportion of wear attributable to another factors is the largest. The reason for this situation lies in the lack of covered (heated) parkings in cold climate areas, both in the main location of cars and at intermediate points along their track. The next reason is the lack of basic means of mechanization for loading and unloading operations at the clientele. That is why car drivers, in order to maintain the thermal regime of the engine and create the necessary comfort in the cab, are forced to not turn off the car engines during the entire cold season. And it leads to a significant loss of motor resources. Sometimes drivers are forced to jam car engines for a period of cooling of the coolant to a temperature of 20degrees $-00{ }^{\circ} \mathrm{C}$. The last method increases the number of starts, which also reduce motor resources. A similar situation happened on the details of the transmission (Figure 4).

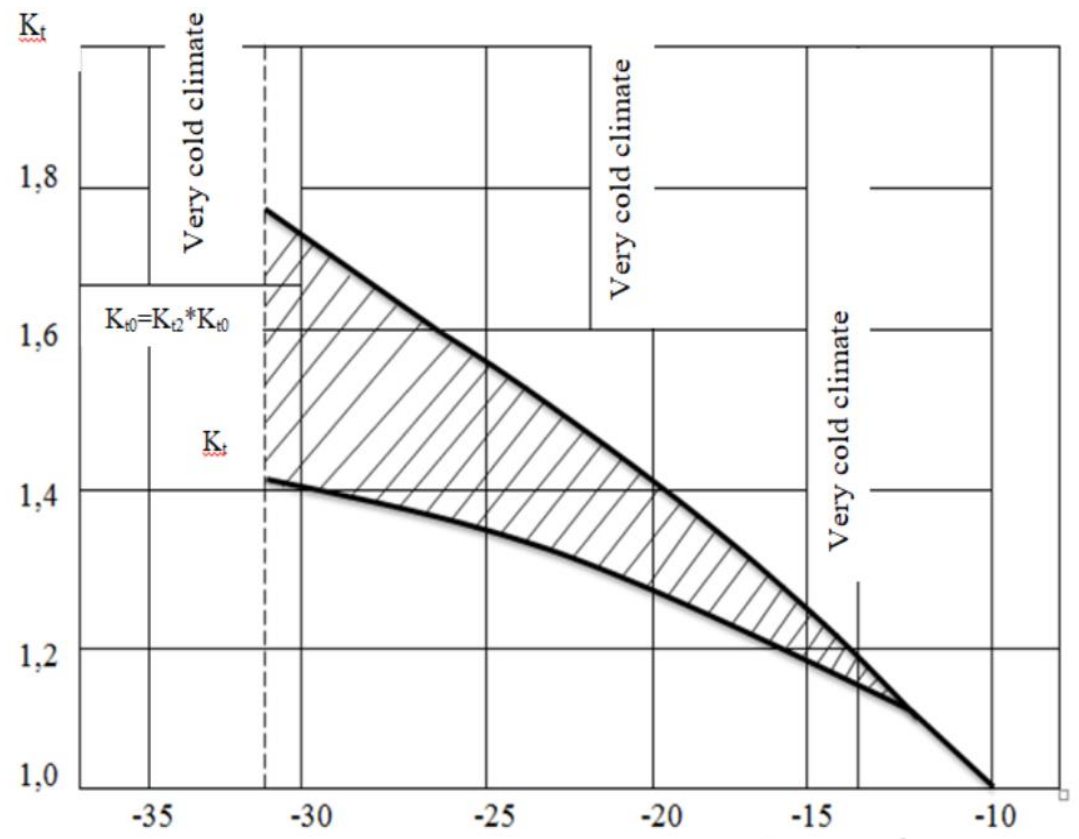

Average ambient temperature in winter, ${ }^{\circ} \mathrm{C}$

Fig. 4. Change of the generalized coefficient of adjustment of the norms of consumption rates of transmission units and its components by operation areas. 


\section{Conclusions}

Coefficient increase $\mathrm{K}_{\mathrm{t} 2}$, connected with an increase in the specific load in the units of the power train transmission due to vehicle overcoming the increased air resistance, for a cold climate zone (The Far North), makes 56\% if compared with a temperate climate zone. Therefore, for other reasons (the area enclosed between the lines $\mathrm{K}_{\mathrm{t} 2}$ and $\mathrm{k}_{\mathrm{to}}$ ) a significant part of the resource of transmission units is also accounted - 44\%. First of all, these reasons include the increased wear of transmission units during the engine start-up especially when the vehicle starts after long-time parking at air temperatures especially at air temperatures below the pour point of transmission oil. In this case, the power transmission gearwheels cut a hole in the frozen oil and are located under this adverse grease conditions for a relatively long time (15 - 20 minutes) - until the transmission warms up and the oil temperature in its units will rise to plus 20 -30 degrees C. Transmission warming up and high oil temperature provide its secure entry into the rubbing zone and the formation of a firm oil membrane on contact surfaces.

Thus, the separation of car wear units by components not only raises the question of improving the standards for technical operation of cars, but also attracts attention to the problem of developing the industrial and technical base of vehicles in cold climates.

\section{References}

1. J.R. Rego, M.A. Mesquita, Int. J. Production Economics 161, 1-16 (2015)

2. B. Kareem, A.S. Lawal, Engineering Failure Analysis 56, 69-79 (2015)

3. A. Bacchetti, N. Saccani, Omega 40, 722-737 (2012)

4. P. Sharma, Reliability Engineering and System Safety 168, 274-289 (2017)

5. K. Antosz, IFAC-Papers On Line 49-12, 1389-1393 (2016)

6. D. Lengu, European Journal of Operational Research 235, 624-635 (2014)

7. Y. Ding, Computers and Electronics in Agriculture 151, 104-117 (2018)

8. Yaoguang Hu, Yu Liu, Zhe Wang, Jingqian Wen, Jinliang Li, Jie Lu, Biosystems engineering 190, 201-217 (2020)

9. N. Stupak, Environmental Science \& Policy 68, 10-19 (2017)

10. A. Osmakova, New Biotechnology 40, 76-81 (2018)

11. S. Zhu, Reliability engineering and System Safety 193, 106600 (2020)

12. S. Van der Auweraer, R. Boute, International Journal of Production Economics 213, 138-149 (2019)

13. S.A. Al-Suhaibani, M.F. Wahby, Society of Agricultural Sciences 16, 294-298 (2017)

14. M. Buraev, P. Ilyin, S. Ilyin, A. Shisteev, A. Anosova, IOP Conference Series: Materials Science and Engineering 632(1) (2019) doi: 10.1088/1757899X/632/1/012019

15. Y.M. Krakovsky, A.N. Luzgin, Y.M. Ivanyo, IOP Conference Series: Materials Science and Engineering 481(1), 012003 (2019) 